
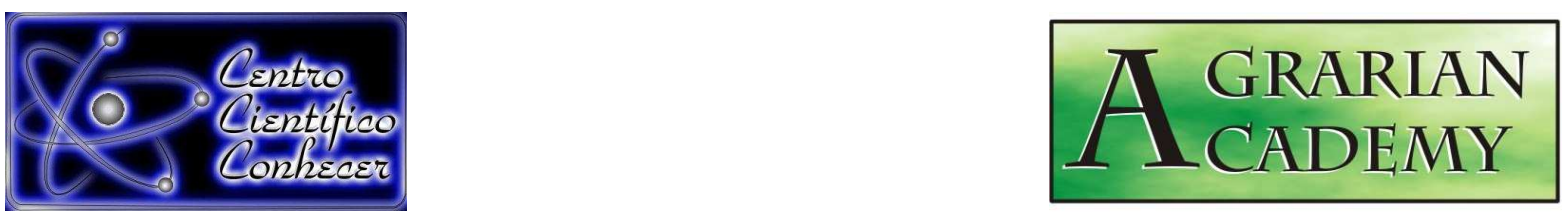

\title{
CONSERVAÇÃO PÓS-COLHEITA DE BANANA 'MAÇÃ' COM REVESTIMENTO COMESTÍVEL A BASE DE FÉCULA DE MANDIOCA
}

Amara Maria da Silva ${ }^{1} ;$ Moisés Ambrósio ${ }^{2} ;$ Damaris Suelen Nascimento ${ }^{3} ;$ Amanda Nogueira de Albuquerque ${ }^{3}$; Willian Krause ${ }^{4}$

1. Engenheira Agrônoma pela Universidade do Estado de Mato Grosso, Tangará da Serra-MT, Brasil. ambrosio_20007@hotmail.com

2. Pós-graduando em Genética e Melhoramento de Plantas pela Universidade do Estado de Mato Grosso, Tangará da Serra-MT, Brasil.

3. Professora mestre da Universidade do Estado de Mato Grosso, Tangará da SerraMT, Brasil.

4. Professor Doutor do programa de pós-graduação em Genética e Melhoramento de Plantas da Universidade do Estado de Mato Grosso, Tangará da Serra-MT, Brasil.

Recebido em: 01/07/2015 - Aprovado em: 31/07/2015 - Publicado em: 21/08/2015

\section{RESUMO}

A pós-colheita de banana 'Maça' muitas vezes é limitada pela deteriorização fisiológica causada pelo excessivo amadurecimento da fruta. Desta forma, este trabalho objetivou avaliar o efeito de concentrações de fécula de mandioca utilizadas como revestimento comestível sobre as características físico-químicas de frutos de banana 'Maça' durante o período armazenamento em temperatura ambiente, com média de $25^{\circ} \mathrm{C}$ e umidade relativa médi a de $41 \%$. Os frutos foram colhidos no assentamento Bezerro Vermelho, no município de Tangará da Serra/MT. O delineamento foi inteiramente casualizado em esquema fatorial $5 \times 5$ (épocas $x$ concentrações de fécula de mandioca). Os frutos foram imersos nas suspensões $0,2,4,6$ e $8 \%$ de concentração de fécula de mandioca. As avaliações foram realizadas aos $0,4,8,12$ e 16 dias de armazenamento para as variáveis, sólidos solúveis (SS), pH, acidez titulável (AT), relação sólidos solúveis e acidez titulável (SS/AT), e até 12 dias de armazenamento para perda de massa fresca (PMF), cor de casca (CC), e vida útil (VU). A utilização do biofilme a base de fécula de mandioca na concentração de $8 \%$ demonstrou ser uma opção viável para conservação pós-colheita de frutos de banana 'Maça' pois além de ser comestível e de baixo custo, proporcionou o aumento da vida útil, retardando o amadurecimento e conservando a firmeza do fruto.

PALAVRAS-CHAVE: biofilme, Musa acuminata, vida útil. 


\title{
POSTHARVEST CONSERVATION OF BANANA 'MACE' WITH EDIBLE CASSAVA STARCH BASED COATING
}

\begin{abstract}
The post harvest banana 'Mace' is often limited by the physiological deteiorização caused by execessivo ripening fruit. Thus, this study aimed to evaluate the effect of cassava starch concentrations used as an edible coating on the physicochemical characteristics of banana 'Mace' fruit 'during the storage period at room temperature averaging $25{ }^{\circ} \mathrm{C}$ and a relative humidity $41 \%$. The f ruits were harvested in the Red Calf settlement, in Tangará da Serra/MT. The design was completely randomized in a factorial $5 \times 5$ (times $\times$ cassava starch concentrations). The fruits were immersed in suspensions $0,2,4,6$ and $8 \%$ of cassava starch concentration. The evaluations were performed at $0,4,8,12$ and 16 days of storage for variables, soluble solids (SS), $\mathrm{pH}$, titratable acidity (TA), soluble solids/ titratable acidity relation (SS / AT), and up to 12 storage days for fresh mass loss (PMF), peel color (CC), shelf life (VU). The use of biofilm cassava starch based on the concentration of $8 \%$ has proven to be a viable option for postharvest banana 'Mace' fruit conservation as well as being edible, low-cost, provided the increased lifespan, delaying its ripening and preserving the firmness of the fruit
\end{abstract}

KEYWORDS: biofilm, Musa acuminata, , useful life.

\section{INTRODUÇÃO}

A banana (Musa ssp) é uma excelente fonte de minerais e vitaminas, desta forma, apresenta uma enorme importância social por ser uma fonte barata de energia aos consumidores, e as características de baixa acidez e textura macia a indicam para o consumo por crianças e idosos (SARMENTO et al., 2012).

O Brasil no cenário mundial é o quinto maior produtor de banana, responsável por $6,8 \%$ do volume produzido, sendo superado pela Índia, China, Filipinas e Equador com valores de 27,7, 9,7, 8,6 e 6,9\%, respectivamente (EMBRAPA, 2014). A produção nacional de banana é superada apenas pela produção de laranja. Nesse contexto, o Brasil é o maior consumidor mundial da fruta representando relevante importância na alimentação (IBGE, 2013). A região Centro Oeste é a quarta maior produtora da cultura, e o Estado de Mato Grosso assume a terceira posição da região (IBGE, 2011). O consumo mundial de banana é de aproximadamente 10,38 $\mathrm{kg} \mathrm{habitante}^{-1}$ ano $^{-1}$ e no Brasil atinge aproximadamente $31 \mathrm{~kg}^{\text {habitante }}$ ano $^{-1}$ (EPAGRI/CEPA, 2014), cultura esta que faz parte do hábito alimentar das populações mais carentes.

Segundo MAPA (2012) a banana, junto com a maçã e uva vêm apresentando crescente importância no mercado nacional e internacional através da participação nas exportações de frutas frescas atingindo o percentual de $33 \%$. No entanto, a maior participação e aproveitamento da produção são limitados por danos e perdas causados durante toda a cadeia produtiva, onde mais de $5 \%$ de perdas ocorrem na produção, $2 \%$ em embalagem, $10 \%$ no atacado, $15 \%$ no varejo e $8 \%$ no consumidor (SOUZA, 1995). E a partir da década de 90, com a maior demanda do mercado por frutos de qualidade, determinadas regiões brasileiras, como o Vale do Ribeira, 0 
Planalto Paulista, litoral de Santa Catarina, o norte de Minas Gerais e o Vale do Açu (RN) já começaram a apresentar uma evolução no manejo pós-colheita da banana.

As perdas possuem diferentes origens, podem ser fisiológicas, microbiológicas e mecânicas as quais merecem destaque, pois quando ocorrem, influenciam diretamente nas perdas fisiológicas e microbiológicas (OLORUNDA, 2000). Por ser uma fruta de padrão respiratório climatérico, a banana sofre intensas transformações bioquímicas após a colheita, e a respiração é altamente influenciada por fatores externos como os danos mecânicos que acarretam no amassamento diminuindo a vida útil dos frutos (VIVIANI \& LEAL, 2007).

Segundo CHITARRA \& CHITARRA (2005), a banana possui uma característica importante entre as frutas climatéricas, devido a larga faixa de maturidade fisiológica, o que permite ser colhida e induzida a maturação com excelente qualidade. Isto permitiu o estabelecimento da maturação comercial dos frutos como atividade rotineira.

A forma adequada de armazenamento de bananas é de suma importância, pois a qualidade destas frutas sofre influência da temperatura e umidade relativa do ar. A variação de temperatura pode aumentar a velocidade de maturação, assim como interfere no estágio da cor de casca. Já a umidade relativa influencia na perda de peso e favorece a incidência de fungos (SILVA \& MELLO, 2013).

De acordo com SARATÓPOULOS \& FERNANDES (2009), as embalagens desenvolvidas para frutas e hortaliças visam retardar a respiração, amadurecimento, senescência e as diversas modificações indesejáveis resultantes dos processos fisiológicos. Com o interesse de reduzir as perdas pós-colheita de alimentos e simultaneamente diminuir o desperdício de embalagens de fontes não renováveis vem se adotando o uso de novos materiais de embalagens de fontes renováveis, como filmes biodegradáveis (OLABARRIETA, 2005). Desse modo, a seleção de filme com permeabilidade compatível à taxa de respiração do produto e controle da temperatura são requisitos importantes na conservação pós-colheita (AGOSTINI et al., 2014).

O uso de revestimento a base de amido é uma nova tecnologia que se baseia na formação de um plástico biodegradável a base de amido termoplástico, que possui as características desejáveis a embalagens para alimentos, possuindo baixo custo, alta eficiência, fina espessura, além da possibilidade de carregar compostos antimicrobianos e antioxidantes (KROTCHA \& MULDER, 1997).

O amido encontrado na mandioca apresenta características desejáveis para ser utilizado como revestimento, pois é comestível, de baixo custo e de fácil manipulação (LIMA, 2010). Dessa forma, é também considerada a matéria prima mais adequada para produção de biofilme, pois torna as hortaliças e frutos mais atrativos para comercialização (LUVIELMO \& LAMAS, 2012).

Diante disso, o presente estudo objetivou avaliar o efeito de concentrações de fécula de mandioca como película de revestimento sobre as características físicoquímica de frutos de banana "maçã" visando prolongar a vida útil. 


\section{MATERIAL E MÉTODOS}

Os frutos de banana 'maçã' foram colhidos no assentamento Bezerro Vermelho localizado no município de Tangará da Serra - MT. O clima da região é tropical, apresentando estações bem definidas, sendo uma estação seca de maio a setembro e respectivamente uma estação chuvosa de outubro a abril. A precipitação média anual varia de 1300 a $2000 \mathrm{~mm}$ ano, com temperatura anual variando entre 16 a $36^{\circ} \mathrm{C}$ (MARTINS et al., 2010).

Os frutos foram colhidos em 16 de abril de 2013 e transportados para o laboratório acondicionados em caixas plásticas, sendo estes envoltos individualmente por jornal para evitar danos mecânicas. O delineamento utilizado foi 0 inteiramente casualizado no esquema fatorial $5 \times 5$ (\% de concentrações de fécula de mandioca $x$ épocas de avaliações) com quatro repetições. As unidades experimentais utilizadas foram constituídas de um buquê com quatro frutos no estágio de maturação 2 (verde com traços amarelos). Designou-se uma parcela especial (testemunha) para avaliar as variáveis perda de massa fresca (PM), cor de casca (CC) e vida útil dos frutos (VU).

Foi realizada a despenca dos cachos imergindo os frutos imediatamente em um tanque com água e detergente neutro, em seguida os buquês foram selecionados e imersos em uma solução de hipoclorito de sódio a $0,5 \%$ por três minutos.

O preparo da solução de fécula de mandioca deu-se através da suspensão do amido em $200 \mathrm{~mL}$ de água destilada nas concentrações de 0, 2, 4, 6 e 8\% de fécula de mandioca, e posteriormente, o volume completado para um litro. Em seguida, a solução foi aquecida a $70^{\circ} \mathrm{C}$ e resfriada em temperatura ambiente. Os frutos foram imersos na solução de fécula por um minuto e acondicionados em bandeja de poliestireno (LUCENA et al., 2004).

Em seguida os frutos foram armazenados no laboratório de melhoramento de plantas em condições ambientes à temperatura média de $25^{\circ} \mathrm{C}$ e umidade relativa de $41 \%$. As variáveis, sólidos solúveis (SS), firmeza de polpa (FP), e relação (SS/AT) pH, acidez titulável (AT), foram avaliadas nas épocas $0,4,8,12$ e 16 dias após aplicação do biofilme e as variáveis cor da casca (CC), perda de massa (PM) e vida útil (VU) foram avaliadas até os 12 dias de armazenamento.

O teor de sólidos solúveis (SS) foi determinado através da leitura direta em refratômetro digital modelo RTD-45, expresso em Brix (INSTITUTO ADOLFO LUTZ, 2008). A firmeza (FP) foi determinada com o uso do penetrômetro PTR-100 com ponteira de $8,0 \mathrm{~mm}$ de diâmetro, medida em dois pontos opostos do fruto, após a remoção da casca e expressa em Newtons $(\mathrm{N})$. A relação SS/AT foi obtida pelo quociente entre as duas variáveis (sólidos solúveis e acidez titulável). $\mathrm{O} \mathrm{pH}$ foi determinado através de um potenciômetro digital previamente calibrado com soluções padrões de pH 7,0 e 4,0 (INSTITUTO ADOLFO LUTZ, 2008) de amostras de 5 gramas de polpa triturada, macerada e diluída em $50 \mathrm{~mL}$ de água destilada. A acidez (AT) foi determinada através da titulação com solução de $\mathrm{NAOH}$ a $0,1 \mathrm{M}$ e com indicador fenolftaleína a 1\%, expressa em porcentagem de ácido málico em $5 \mathrm{~g}$ de polpa.

A variável cor de casca foi analisada visualmente com o auxílio da escala de notas de Von Loeseck (PROGRAMA BRASILEIRO PARA MODERNIZAÇÃO DA HORTICULTURA, 2004), atribuindo notas de 1 a 7 , onde 1 (totalmente verde), 2 (verde com traços amarelos), 3 (mais verde que amarelo), 4 (mais amarela que verde), 5 (amarela com ponta verde), 6 (totalmente amarela) e 7 (amarela com áreas marrons). 
A perda de massa fresca foi obtida pela diferença entre a massa inicial dos buquês e os valores obtidos a cada avaliação através de pesagem dos frutos em uma balança analítica de precisão de $0,01 \mathrm{~g}$ (OLIVEIRA, 2010). A determinação da vida útil dos frutos foi determinada em função do número necessário de dia para atingir o estagio de maturação 7 e em condição de consumo (OLIVEIRA, 2010).

Os dados foram submetidos à análise de variância e a análise de regressão, utilizando o programa estatístico SISVAR (FERREIRA, 2011).

\section{RESULTADOS E DISCUSSÃO}

Não houve interação significativa entre concentrações de fécula de mandioca e o tempo de armazenamento. Entretando houve efeito significativo das concentrações de fécula de mandioca para as variáveis sólidos solúveis (SS) e firmeza de polpa (FM) a $5 \%$ de probabilidade. Já o fator época influenciou significativamente as variáveis sólidos solúveis (SS), $\mathrm{pH}$, firmeza de polpa (FM) e acidez titulável (AT) a 1\% de probabilidade.

Em relação ao teor de sólidos solúveis houve um efeito linear do fator concentrações de fécula sobre os frutos, de modo que a maior concentração de $8 \%$ proporcionou o menor teor de sólidos solúveis (15,2®rix). Isto demonstra que 0 revestimento com fécula de mandioca retardou 0 amadurecimento $e$, consequentemente, a menor conversão do amido em açúcares simples. $\mathrm{Na}$ concentração zero, observou-se maior teor de sólidos solúveis atingindo teor de 16,9Brix (Figura 1A).

Para o fator dias de armazenamento houve efeito quadrático, apresentando ponto de máxima aos 15,8 dias correspondendo a 22,78Bix (Figura 1B). Assim, observa-se que com o amadurecimento do fruto há o acúmulo de açúcares, aumentando o teor de sólidos solúveis (OLIVEIRA, 2010). Os resultados observados neste trabalho referentes aos teores de sólidos solúveis estão de acordo com a faixa de variação de 25 Brix citada por CHITARRA \& CHITAR RA (2005) e PIMENTEL et al. (2010). Isto ocorre devido a hidrólise do amido que acarreta neste acúmulo de açúcares, além da ação do revestimento aplicado que concentra $\mathrm{Co}_{2}$ e reduz $\circ \mathrm{O}_{2}$, isto propicia a redução do transporte dos gases e da umidade, afetando o processo de maturação dos frutos (ALMEIDA et al., 2006; OLIVEIRA, 2010).

$\mathrm{O} \mathrm{pH}$ variou durante o período de armazenamento, ocorrendo redução gradativa, atingindo o ponto de mínima aos 9,11 dias e pH de 4,97 (Figura 1C). De acordo com ROCHA (1984) os valores de pH diminuem após a colheita, comportamento este, explicado pelo aumento da acidez em virtude da degradação da parede celular. LUCENA et al. (2004) observaram redução significativa do pH em bananas 'Nanicão' revestidas com fécula de mandioca até 0 6으 dia de armazenamento, após este período houve um aumento do $\mathrm{pH}$.

Os teores de acidez titulável aumentaram com o tempo de armazenamento, apresentando o ponto máximo aos 11,44 dias com 0,45 de acidez (Figura 1D). Os resultados encontrados estão de acordo com a faixa aceitável, que segundo FERNANDES (1979) é de 0,17 a 0,67\%. Segundo CHITARRA \& CHITARRA (2005), os principais ácidos presentes na banana são o málico, cítrico e oxálico, e o aumento da acidez é justificado pelo metabolismo dos ácidos tricarboxílicos durante o amadurecimento. De acordo com LUCENA et al. (2004) o comportamento da acidez é inversamente proporcional ao do $\mathrm{pH}$, e que em bananas ao contrário de outras frutas com o amadurecimento ocorre o aumento da acidez (OLIVEIRA, 2010). 

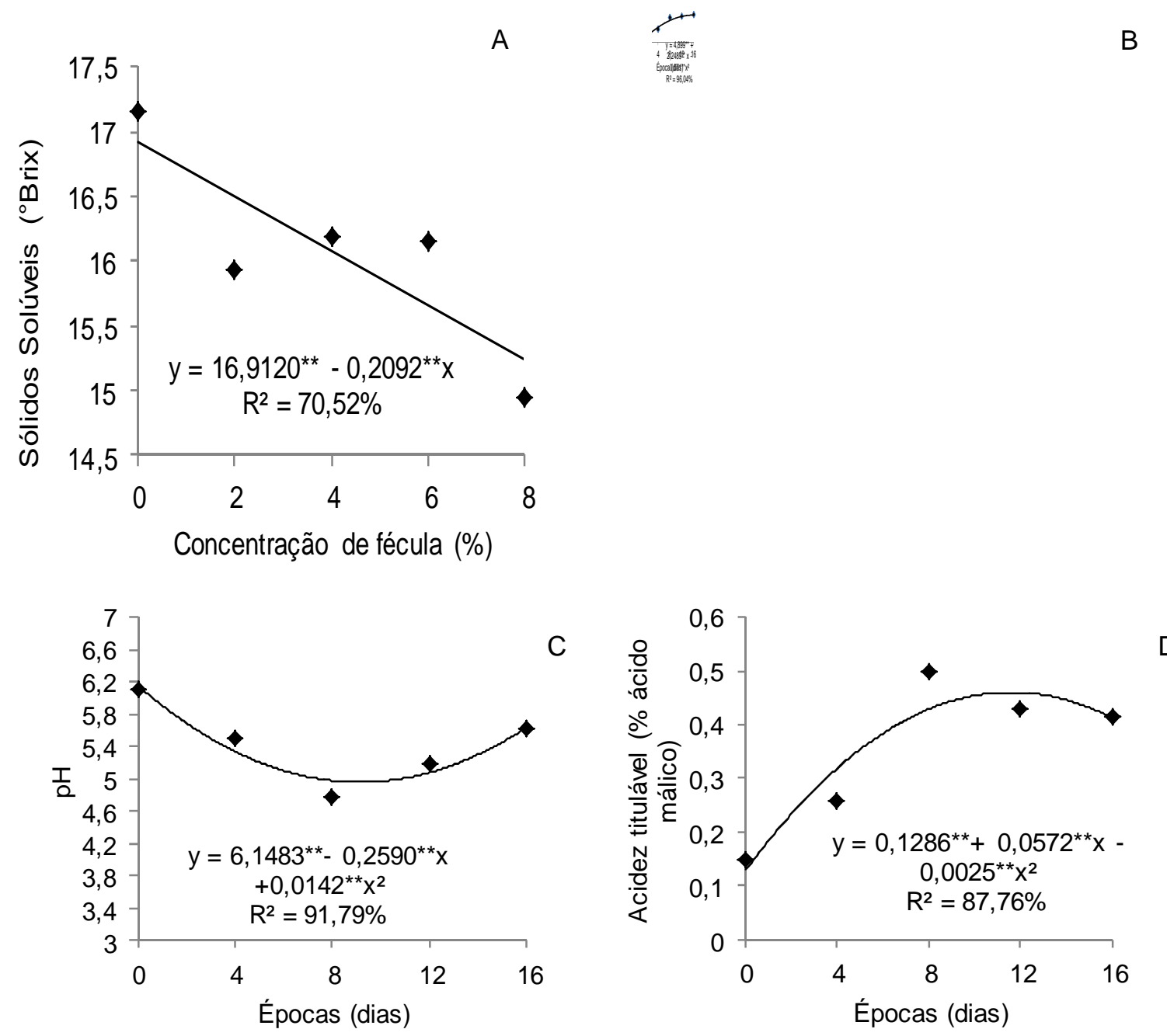

FIGURA 1. Sólido Solúveis (A e B), pH (C) Acidez titulável (D) de frutos de banana 'Maça' submetidos as diferentes concentrações de fécula de mandioca durante os dias armazenamento.

Em relação à firmeza de polpa (FM) a concentração de fécula de $8 \%$ proporcionou a maior firmeza dos frutos de $56,4 \mathrm{~N}$ (Figura 2A), indicando que a perda normal da firmeza decorrente ao amadurecimento foi alterada devida a utilização da alta concentração de fécula de mandioca, a qual aumentou a barreira durante as trocas gasosas de forma a reduzir eficientemente o metabolismo dos frutos. VILA et al. (2006) afirmam que frutos envolvidos com o revestimento a base de fécula de mandioca apresentam menor evolução da atividade enzimática da poligalacturonase (PG) e pectinometilesterase (PME) e sugerindo que tais concentrações do biopolímero foram capazes de reduzir o metabolismo dos frutos a ponto de diminuir o amaciamento da polpa. Resultados que estão de acordo com SILVA et al. (2011) que encontraram comportamento semelhante em bananas 'Prata' submetidas a concentrações de 0, 2, 4, 6, 8 e 10\% de fécula de mandioca onde obtiveram valores máximos de $50 \mathrm{~N}$ para 4,6 e $8 \%$ de fécula.

Os dias de armazenamento influenciaram de forma linear na firmeza dos frutos, onde aos 16 dias atingiu 17,04 N de firmeza (Figura 2B). SARMENTO et al. (2015) observaram em banana 'Prata Catarina' que durante o período de armazenamento, os valores de firmeza da polpa das frutas reduziram significativamente na medida que avançaram a maturação, onde inicialmente, AGRARIAN ACADEMY, Centro Científico Conhecer - Goiânia, v.2, n.03; p. 28 2015 
verificou-se valor de firmeza da polpa de $46,45 \mathrm{~N}$, e ao final do armazenamento de $5,69 \mathrm{~N}$, o que representou uma redução de $87,58 \%$. OLIVEIRA (2010) descreve que, a firmeza dos frutos esta associada à composição da parede celular, que é constituída de hemicelulose, celulose, ligninas, pectinas, entre outros. Com o avanço do amadurecimento, estas substâncias vão se degradando, devido à coesão entre as células e o fruto, por sua vez, perde a resistência dos tecidos.

Para a variável cor de casca houve efeito quadrático, verificando o ponto de máxima na concentração de $0,23 \%$ que proporcionou nota de cor de casca de 5,18 , equivalente a frutos com cor amarela com ponta verde (Figura $2 \mathrm{C}$ ). CASTRICINI (2009) utilizando diferentes concentrações de fécula de mandioca em mamão 'Golden' atribuíram este comportamento ao efeito positivo da atmosfera modificada que colaborou para maior retenção de clorofila, consequentemente, maior concentração de $\mathrm{CO}_{2}$ e menor de $\mathrm{O}_{2}$ e de etileno na polpa do fruto, ajudando a reduzir as taxas metabólicas e retardando a coloração da casca. Segundo PRILL et al. (2012) a variação da coloração na casca dos frutos ocorrida durante o amadurecimento, ocorre possivelmente pelo processo de degradação da clorofila com relação ao metabolismo respiratório dos frutos.

Observou-se no decorrer do período de armazenamento uma mudança linear na cor de casca, apresentando nota 6,75 (casca totalmente amarelada) aos 12 dias, o que indica a mudança do estágio de maturação nos frutos (Figura 2D). Conforme SILVA et al. (2006) este aumento na coloração da casca é referente aos pigmentos de carotenoides que proporciona a cor amarela aos frutos através da degradação intensa das clorofilas, e conforme a velocidade desta mudança de cor, pode ser utilizada como indicativo de constatação de agilidade do amadurecimento dos frutos. A associação da cor de casca e grau de maturação está diretamente ligada ao sabor da fruta, pois quanto maior o estágio de maturação maior o teor de açúcares na polpa, e consequentemente mais agradável ao paladar. Desta forma, frutas no estádio 7 de maturação são desejáveis, pois indicam ponto ideal de maturação (FRUTIFATOS, 2002).

A perda de massa dos frutos não foi influenciada pela aplicação do biofilme, já que tanto os frutos a $0 \%$ quanto os $8 \%$ apresentaram aumento da perda de massa fresca durante as épocas de armazenamento atingindo o ponto de máxima aos 11,6 dias com 9,4\% de perda de massa fresca (Figura 2E). SILVA et al. (2011) constataram que os revestimentos a base de fécula de mandioca não influenciaram na perda de massa em bananas 'Prata', os frutos perderam massa gradativamente até os 11 dias de armazenamento atingindo 9,5\%. Segundo TRIGO (2010) a perda de água dos frutos resulta na perda de massa fresca e na qualidade, o que acaba depreciando a aparência do produto (CASTRICINI et al., 2010). No presente trabalho as perdas ficaram abaixo de $10 \%$ o que de acordo com CHITARRA \& CHITARRA (2005) é aceitável para frutos e hortaliças, pois não compromete a aparência do produto. OLIVEIRA et al. (2009) encontraram valores superiores de perda de massa em banana 'Pacovan', onde as perdas foram maiores no $4^{\circ}$ e 6으 de armazenamento atingindo valores de 12 a $15 \%$ respectivamente.

Apesar dos resultados estarem adequados a faixa aceitável, verificou-se que os frutos apresentaram aspecto visual limitado uma vez que ocorreu o murchamento dos mesmos. Tal fato pode ter ocorrido devido à umidade relativa no local de armazenamento estar abaixo do recomendado, sendo necessário $90 \%$ de umidade. Segundo CHITARRA \& CHITARRA (2005) o murchamento acarreta na redução da comercialização dos frutos; 
Em relação à vida útil dos frutos, foi observado efeito linear da concentração de fécula, a concentração de $8 \%$ proporcionou vida útil nos frutos de 16,28 dias enquanto que sem a aplicação do biofilme foi de apenas 8,6 dias (Figura 2F), demonstrando o efeito do revestimento em retardar o amadurecimento dos frutos $\mathrm{e}$ prologando a vida útil (OLIVEIRA, 2010).
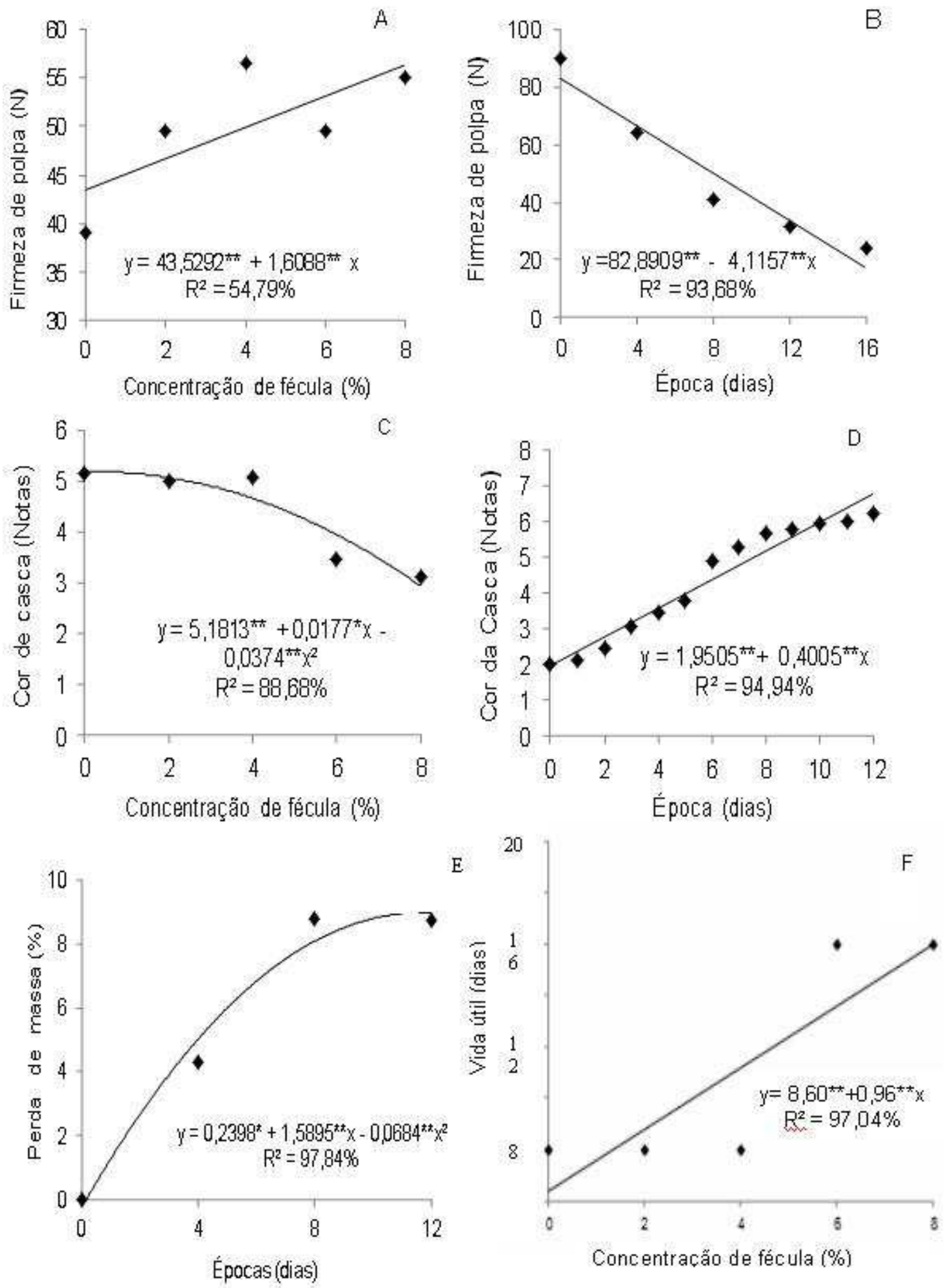

FIGURA 2. Firmeza de polpa (A e B), Cor da casa (C e D), Perda de massa (E) e Vida útil (F) de frutos de banana 'Maçã' submetidos as diferentes concentrações de fécula de mandioca durante os dias de armazenamento. 


\section{CONCLUSÃO}

A utilização do biofilme a base de fécula de mandioca na concentração de $8 \%$ demonstrou ser uma opção viável para conservação pós-colheita de frutos de banana 'Maça' pois além de ser comestível e de baixo custo, proporcionou o aumento da vida útil, retardando o amadurecimento e conservando a firmeza do fruto.

\section{REFERÊNCIAS}

AGOSTINI, J. S.; SCALON, S de P. Q.; LESCANO, C. H.; SILVA, K. E. da; GARCETE, G.J. Conservação pós-colheita de laranjas Champagne (Citrus reticulata $\times$ Citrus sinensis). Brazilian Journal of Food Technology, Campinas, v. 17, n. 2, p. 177-184, 2014.

ALMEIDA, G. C.; VILAS BOAS, E. V. de B.; RODRIGUES, L. J.; DE PAULA, N. R. Atraso do amadurecimento de banana 'maçã' pelo 1-MCP, aplicado previamente à refrigeração. Revista Brasileira de Fruticultura, Jaboticabal, v. 28, n. 2, p. 319-321, 2006.

CASTRICINI, A. Aplicação de revestimentos comestíveis para conservação de mamões (Carica papaya L.) 'Golden'. 2009. 128f. Tese (Doutorado em Ciências), Universidade Federal Rural do Rio de Janeiro.

CASTRICINI, A.; CONEGLIAN, R. C. C.; VASCONCELLOS, M. A. da S. Qualidade e amadurecimento de mamões 'golden' revestidos por película de fécula de mandioca. Revista trópica - Ciências Agrárias e Biológicas. v.4, n.1, p.32, 2010.

CHITARRA,M.I.F.;CHITARRA,A.B. Pós-colheita de frutas e hortaliças. fisiologia e manuseio. Lavras:ESAL/FAEPE, 2005. 293p.

EMPRESA BRASILEIRA DE PESQUISA AGROPECUÁRIA. Banana. Disponível $\mathrm{m}:<h t t p: / / w w w . c n p m f . e m b r a p a . b r / i n d e x . p h p ? p=$ pesquisaculturas_pesquisadasbana

a.php\&menu=3>.Acesso em: 14 fev. 2014.

EMPRESA DE PESQUISA AGROPECUÁRIA E EXTENSÃO RURAL DE SANTA CATARINA. Centro de Socioeconomia e Planejamento Agrícola. Banana. In: Síntese Anual da Agricultura de Santa Catarina - 2010-2011. Disponível em: Acesso em: 14 fev. 2014.

FERNANDES, K.M. Physical changes during ripening of silver bananas. Journal of Food Science, Chicago, v.44, n.4, p.1254-1255, 1979.

FERREIRA, D.F. Sisvar: a computer statistical analysis system. Ciência e Agrotecnologia, Lavras, v.35, n.6, p. 1039-1042, 2011.

FRUTIFATOS. Bananas nanica e prata conquistam a preferência. Frutifatos, Brasília. v.2, n.2, p.1 8-19, jun. 2002. 
INSTITUTO ADOLFO LUTZ. Métodos físico-químicos para análise de alimentos. 2008. Disponível em: <http://www.ial.sp.gov.br/index. php?option =com_remository\&ltemid=0\&func=select\&orderby=1 >. Acesso em: 27 mar. 2013 .

INSTITUTO BRASILEIRO DE GEOGRAFIA E ESTATÍSTICA IBGE -. Disponível em: <http://www.sidra.ibge.gov.br>. Acesso em: 20 ago. 2012.

KROTCHA J.M.;MULDER ,J. Edible and biodegradable polymer films: challenges and opportunities. Food Tecnology, Baltimore, v.51, n.02, p.60-74, 1997.

LIMA, O.L.B. Conservação pós-colheita de mamão 'Sunrise Solo' com uso de revestimento naturais. 53f. 2010. Dissertação (Mestrado em produção vegetal) Programa de pós-graduação em Agronomia da Universidade do Acre.

LUCENA, C.C.; SILVA, A. C. DA; SILVA, A. C.; FEITOSA, H. DE O.; ALMEIDA, F. F. D. DE ; CONEGLIAN, R. C. C.; VASCONCELLOS, M. A. DA S. Efeito da película de amido na conservação pós-colheita de frutos de banana cv. 'Nanicão'. Revista Agronomia, Rio de Janeiro, v.38, n.2, p.34-37, 2004.

LUVIELMO, M.M.; LAMAS, S.V. Revestimentos comestíveis em frutas. Estudos Tecnológicos em Engenharia, Pelotas, v.8, n.1, p. 8-15, 2012.

MARTINS, J. A.; DALLACORT, R.; INOUE, M. H.; SANTI, A.; KOLLING, E. M.; COLETTI, A. J. Probabilidade de precipitação para a microrregião de Tangará da Serra, Estado do Mato Grosso. Pesquisa Agropecuária Tropical, v.40, p.291-296, 2010.

MINISTÉRIO DA AGRICULTURA, PECUÁRIA E ABASTECIMENTO. Brasil projeções do agronegócio 2011/2012 a 2021/2022. Brasília, 2012, 50 p.

OLABARRIETA, I. Strategies to improve the aging barrier and mechanical properties of chitosan, whey and wheat gluten protein films. 2005. 189f. Tesis (Doutorado em ciência de alimentos) - Department of fibre polymer technology, royal institute of technology Stockholm, Sweden, 2005.

OLIVEIRA, E.B. de L. Conservação pós-colheita de mamão 'Sunrise Solo' com uso de revestimentos naturais. 2010. 55f. Dissertação (Mestrado em Agronomia), Universidade Federal do Acre.

OLIVEIRA, T.C.T.; SANTOS, A.E.O. dos; SILVA, J.R.; OLIVEIRA, L.N. de; BARROS, F.L.L. Atmosfera modificada na conservação pós-colheita de banana cv. Pacovan. In: Congresso de pesquisa e inovação da rede Norte e Nordeste e de Educação tecnológica, 4., Belém, Pará. p.1-7.2009.

OLORUNDA, A.O. Recent advances in postharvest technologies of banana and plantain in Africa. Acta Horticulturae, Uganda, n. 540, p.517-597, 2000.

PIMENTEL, R. M. de A.; GUIMARÃES, F. N.; SANTOS, V. M. dos; RESENDE, J. C. F de. Qualidade pós-colheita dos genótipos de banana PA42-44 e 'Prata-Anã' 
cultivados no norte de minas gerais. Revista Brasileira de Fruticultura, v. 32, n. 2, p. 407-413, Jun. 2010.

PRILL, M.A.S.; NEVES, L. C.; TOSIN, J. M.; CHAGA, E. A.; Atmosfera modificada e controle de etileno para bananas 'prata-anã' cultivadas na Amazônia Setentrional Brasileira. Revista Brasileira de Fruticultura, Jaboticabal, v.34, n.4, p.990-1003, dez. 2012.

PROGRAMA BRASILEIRO PARA A MODERNIZAÇÃO DA HORTICULTURA. Normas de classificação de melão. São Paulo: CEAGESP/Centro de Qualidade em Hortaliças, 2004. 6 p.

ROCHA. J.L.V. Fisiologia pós - colheita de banana. In: 1ำ Simpósio Brasileiro sobre Bananicultura, Jaboticabal. Anais, Universidade de Ciências Agronômicas e Veterinárias de Jaboticabal. p.353-367, (1984).

SARANTOPOULOS, C.I.G.L.; FERNANDES,T. Embalagens ativas e inteligentes para frutas e hortaliças. Campinas: Instituto de tecnologia de alimentos, 2009. 7p. (Boletim informativo, 21). Disponível em $<$ http://ag20.cn ptia.embrapa.br/Repositorio/v21n1_artigo1_000g9ctpcj002wx5ok0u5nfpmnwcr5gg.p df>. Acesso em: 20 abr. 2013

SARMENTO, J. D.A.; MORAIS, P. L. D. de.; ALMEIDA, M. L. B.; SILVA, G. G. da.; SARMENTO, D. H. A.; BATALHA, S. de A.. Qualidade pós-colheita de banana submetida ao cultivo orgânico e convencional. Revista Brasileira de Produtos Agroindustriais, Campina Grande, v.14, n.1, p.85-93, 2012.

SARMENTO, D. H.A; SOUZA, P. A de; SARMENTO, J. D. A; FREITAS, R. V da S; FILHO, M S. Armazenamento de banana 'prata catarina' sob temperatura ambiente recobertas com fécula de mandioca e pvc. Revista Caatinga, Mossoró, v. 28, n. 2, p. $235-241$, abr. - jun., 2015

SILVA, A. A. L.; BONOMO, R. C. F.; CHAVES M. A. REBOUÇAS, K. H.; SANTOS, T. D. R.; OLIVEIRA, C. L. efeitos de revestimentos de amido gelatinizado no armazenamento refrigerado de banana prata (Musa AAB). Revista Brasileira de Produtos Agroindustriais, Campina Grande, v.13, n.3, p.235-241, 2011.

SILVA, A.P.P.; MELLO, B. Colheita e pós-colheita da banana. Universidade Federal de Uberlândia. Disponível em: <http://www.fruticultura.iciag.ufu.br /pos_colheita.html>. Acesso em: 13 abr. 2013.

SILVA. C.S; LIMA, L.C; SANTOS, H.S.; CAMILI, E.C.; VIEIRA; CRYI; MARTIN, C.S.; VIEITES, R.L. Amadurecimento da banana-prata climatizada em diferentes dias após a colheita . Ciência e Agrotecnologia, Lavras, v.30, n.1, p.103-111, 2006.

SOUZA, A.T. Banana. Florianópolis: Instituto de Planejameto e Economia Agrícola de Santa Catarina, 1995. 103 p. (Estudo de economia e mercado de produtos agrícolas, 2). 
TRIGO, J. M. Qualidade de mamão 'formosa' minimamente processado utilizando revestimentos comestíveis. 2010, 105f. (Mestrado) Escola Superior de Agricultura "Luiz de Queiróz", Universidade de São Paulo (USP). 2010.

VILA, M.T.R.; LIMA, L.C.O.; VILAS BOAS, E.V.B.; HOJO, E.T.D.; RODRIGUES, L.J.; PAULA, N.R.F. (2006) Caracterização química e bioquímica de goiabas armazenadas sob refrigeração e atmosfera modificada. Ciência Agrotécnica, Lavras, 31 (5): 1435-1442.

VIVIANI, L.;LEAL, M.P. Qualidade pós-colheita de banana prata anã Armazenada sob diferentes condições. Revista Brasileira de Fruticultura, Jaboticabal, v.29, n.23, p.1-6. 2007. 